\title{
Microstructure and mechanical properties of Sn-9Zn-xAl and Sn-9Zn-xCu lead-free solder alloys
}

\author{
B. YAVUZER*, D. ÖZYÜREK, AND T. TUNÇAY \\ Karabuk University, Technology Faculty, Manufacturing Eng. 78100 Karabuk, Turkey
}

This study investigates microstructures and mechanical properties of the alloys obtained by adding $\mathrm{Cu}(0.7 \%$ and $0.9 \%)$ and $\mathrm{Al}(0.7 \%$ and $0.9 \%)$ to lead-free Sn-9Zn eutectic soldering alloy produced by investment casting method. The results show that $\mathrm{Cu}_{5} \mathrm{Zn}_{8}$ phase has formed in the structure of $\mathrm{Cu}$ added alloys and the $\mathrm{Al}_{2} \mathrm{O}_{3}$ phase has formed due to addition of $\mathrm{Al}$. It was found that small and round-shaped $\mathrm{Al}_{2} \mathrm{O}_{3}$ phase increased the tensile strength of the new alloy compared to the eutectic alloy. In addition, it was observed that the microhardness of $\mathrm{Cu}$ added alloys was lower than that of Sn-9Zn eutectic alloy, but the microhardness of alloys containing Al was higher compared to the other eutectic Sn-9Zn alloy.

Keywords: Sn-Zn lead-free alloys; investment casting; mechanical properties

\section{Introduction}

Tin-lead $(\mathrm{Sn}-\mathrm{Pb})$ alloys are widely used to join and install electronic circuits. These alloys are preferred as soldering alloys in industrial production, especially in electronics sector, due to their low melting temperatures, low cost and good wettability. However, the number of studies on lead-free soldering alloys has been increasing due to adverse effects of lead on environment and human health [1-6]. In addition, the use of soldering alloys containing lead in manufacturing of electronic and microelectronic products has been banned by environmental protection agencies (RoHS and WEEE) [7-10]. Therefore, legislations banning the use of traditional $\mathrm{Sn}-\mathrm{Pb}$ soldering alloys have primarily aimed to improve the mechanical properties of alternative lead-free alloys in order to make them available to use [11-14]. New alloys intended to be used as soldering material must meet a wide range of criteria such as low cost, good wettability, suitable melting temperature, excellent mechanical and electrical conduction, high corrosion resistance, health and environment friendliness. In recent years, there are increasing number of studies on Sn-Ag [15], Sn-Zn [16], Sn-Bi [17], Sn-Cu [18]

*E-mail: bekiryavuzer@gmail.com alloys, and ternary alloys as well as quaternary alloys obtained by adding new elements to these alloys as an alternative soldering alloy to $\mathrm{Sn}-\mathrm{Pb}$ alloys $[19,20]$.

The Sn-9Zn alloy seems to be the closest alternative soldering alloy to $\mathrm{Sn}-\mathrm{Pb}$ soldering alloys. This is due to its low melting temperature, health and environment friendliness, excellent mechanical properties, and low cost compared to other lead-free soldering alloys. On the other hand, the most significant disadvantage of the Sn-9Zn alloy is its low oxidation resistance (since $\mathrm{Zn}$ is a highly active element) and poor wettability. This property of the Sn-9Zn alloy prevents it from being widely used $[11,13]$. With a melting temperature very close to $\mathrm{Sn}-\mathrm{Pb}$ soldering alloy, $\mathrm{Sn}-9 \mathrm{Zn}$ alloy is widely preferred for production. The most significant disadvantage of the high melting temperature of lead-free soldering alloys intended to be used instead of existing soldering alloys is the necessity of replacing many materials used in printedcircuit cards and thus, many existing devices. This causes an increase in production costs. In addition, full understanding of the effect of third and fourth alloy elements added to the alloy on successful application of $\mathrm{Sn}-\mathrm{Zn}$ based solders in interconnecting technology, plays an important role in terms of thermal-mechanical reliability of soldering 
assemblies. For this reason, different alloy elements such as $\mathrm{Ag}, \mathrm{Al}, \mathrm{Cu}, \mathrm{Cr}, \mathrm{In}$ and $\mathrm{Ni}$ are added to Sn-Zn alloys. For example, Yang et al. [21] has reported that various intermetallics, such as $\mathrm{Al}_{2} \mathrm{Cu}$ formed in the structure of the alloy take part in improving the creep strength of the alloy and preventing dislocation moves. Therefore, in this study, the alloys were produced by investment casting adding $\mathrm{Al}$ and $\mathrm{Cu}$ to a Sn-9Zn eutectic alloy at different amounts. Microstructures and mechanical properties of the alloys were examined in an attempt to understand the effect of possible intermetallic compounds (IMCs) on their mechanical properties.

\section{Materials and method}

In this study, alloys with different chemical compositions were produced using investment casting by adding $\mathrm{Al}$ and $\mathrm{Cu}$ to the $\mathrm{Sn}-9 \mathrm{Zn}$ eutectic alloy at different amounts. Chemical compositions of produced alloys can be found in Table 1 .

Table 1. Chemical composition of produced alloys.

\begin{tabular}{c}
\hline Chemical Compositions [wt.\%] \\
\hline \hline Sn-9Zn \\
Sn-9Zn-0.7Cu \\
Sn-9Zn-0.9Cu \\
Sn-9Zn-0.7Al \\
Sn-9Zn-0.9Al \\
\hline
\end{tabular}

In order to produce the alloys given in Table 1 using investment casting, wax models of the samples were prepared first. The molds of the wax models to be used for producing tensile samples were prepared using Al-Si alloy in accordance with EN ISO 6892-1 (ASTM E8/E8M - 13a) standard.

A $1 \mathrm{~kg}$ capacity wax injection device was used to prepare the wax models of the samples. Wax was injected to the metal mold at $73{ }^{\circ} \mathrm{C}$ temperature under $80 \mathrm{kPa}$ pressure. The wax models of the samples were coupled together using an electric soldering iron to form a cluster model. The cluster model was placed in a steel flask with $90 \mathrm{~mm}$ diameter.

The chemical compositions given in Table 1 were prepared using elements $(\mathrm{Sn}, \mathrm{Zn}, \mathrm{Cu}, \mathrm{Al})$ of commercial purity. The elements were melted at different temperatures. Pre-alloying treatment was performed at $350{ }^{\circ} \mathrm{C}$ for $\mathrm{Sn}-9 \mathrm{Zn}$ alloy, and at $400{ }^{\circ} \mathrm{C}$ for other alloys. Since the melting temperatures of $\mathrm{Al}$ and $\mathrm{Cu}$ are higher than those of $\mathrm{Sn}$ and $\mathrm{Zn}$, the liquid metal was kept in the melting furnace at these temperatures for 1 hour to avoid segregation. In the melting operations, a $1 \mathrm{~kg}$ capacity electric furnace and graphite crucible were used.

The pre-alloyed materials were poured into prepared plaster molds in atmospheric environment after the second melting, and the sample production for tensile testing was completed. Temperature measurements during the pouring were done using $\mathrm{NiCr}-\mathrm{K}$ type mineral insulated thermocouples with a diameter of $0.23 \mathrm{~mm}$.

After the casting procedure was completed, the samples were prepared for microstructure examinations using standard metallographic operations. Metallographically prepared samples were etched in a mixture of $100 \mathrm{~mL} \mathrm{H}{ }_{2} \mathrm{O}, 2 \mathrm{~mL} \mathrm{HCl}, 10 \mathrm{~g}$ $\mathrm{FeCl}_{3}$ for 45 seconds and microstructure examinations were performed. In the microstructure examinations, CARL ZEISS ULTRA PLUS GEMINI (FEG) scanning electron microscope (SEM) and energy-dispersion spectroscopy (EDS) were used. In addition, X-ray diffraction (XRD) examinations were performed with a Rigaku D-MAX RINT-2200 series brand device in order to determine the phases formed during the solidification. Shimadzu HMV microhardness tester was used for hardness measurements. Hardness values were measured applying $50 \mathrm{~g}$ load for 20 seconds. The average of five hardness measurements performed on each sample was taken. 1200 grid sandpaper was used for surface cleaning of tensile test samples. After surface cleaning processes, the samples were tested at $1 \mathrm{~mm} / \mathrm{min}$ load rate using Shimadzu AG-IS brand tester that can be adjusted to $50 \mathrm{kN}$ capacity.

\section{Results and discussion}

\subsection{Microstructural characterization}

In the experimental studies, microstructural and mechanical properties of ( $\mathrm{Al}$ and $\mathrm{Cu}$ added) $\mathrm{Sn}-\mathrm{Zn}$ alloys with different chemical compositions were examined. Microstructure SEM images of Sn-9Zn 
alloys with different chemical compositions can be found in Fig. 1.

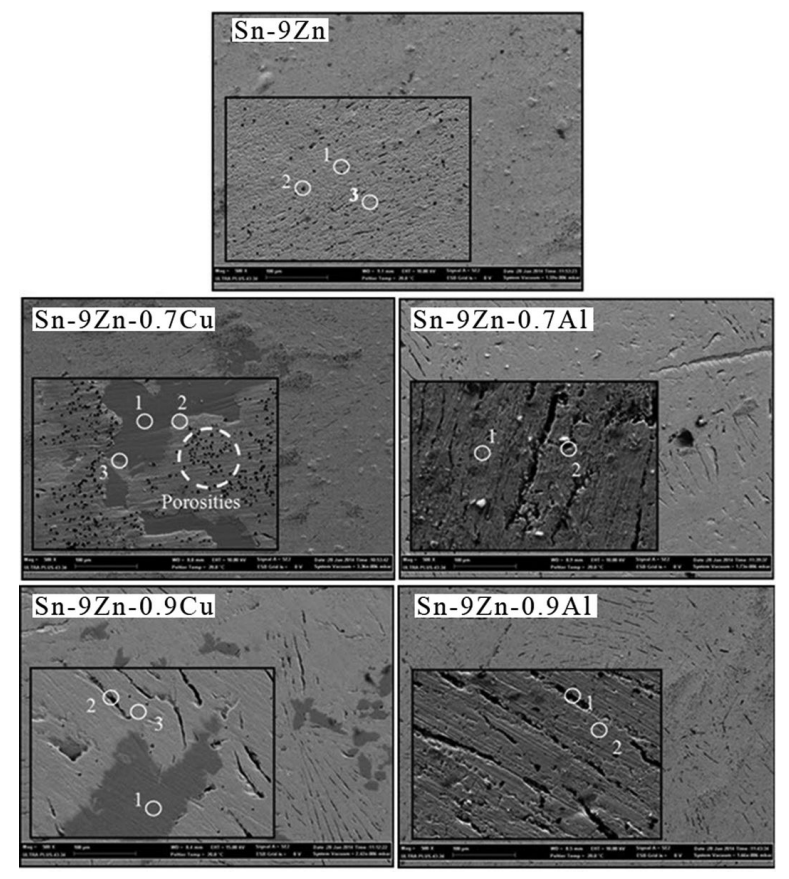

Fig. 1. SEM images of eutectic Sn-9Zn alloy obtained by adding different amounts of $\mathrm{Al}$ and $\mathrm{Cu}$.

As can be seen in the microstructure SEM images in Fig. 1, the matrix structure of the Sn-9Zn alloy contains $\beta$-Sn and $\mathrm{Zn}$-rich phases with homogeneous distribution formed in $\beta$ matrix. In a study by El-Daly et al. [22], Zn-rich areas were reported to form in Sn-Zn eutectic alloy. In the SEM images of alloys produced by adding $\mathrm{Cu}$ to the $\mathrm{Sn}-9 \mathrm{Zn}$ eutectic alloy at different amounts (wt.\% 0.7 and 0.9 ), it was found that $\beta-\mathrm{Sn}$, which is the main matrix, eutectic $\alpha$-Zn and flower-shaped phases were formed. It can be seen from EDS results (Table 2) that the flower-shaped phase consists of $\mathrm{Zn}$ and $\mathrm{Cu}$, and according to XRD results (Fig. 2) shows the formation of $\mathrm{Cu}_{5} \mathrm{Zn}_{8}$ and $\mathrm{CuZn}_{5}$ intermetallic compounds (IMCs) in the structure. It was found that the size of IMCs and percentage ratios in the structure increase with increasing the amount of $\mathrm{Cu}$ addition. Also, it was observed that the $\alpha$-Zn phase formed around IMCs has a thinner structure. In investment casting, pores may occur due to low cooling rate. Previously, it was also reported by Garcia et al. [8] that pores were formed in the microstructure of the alloy.

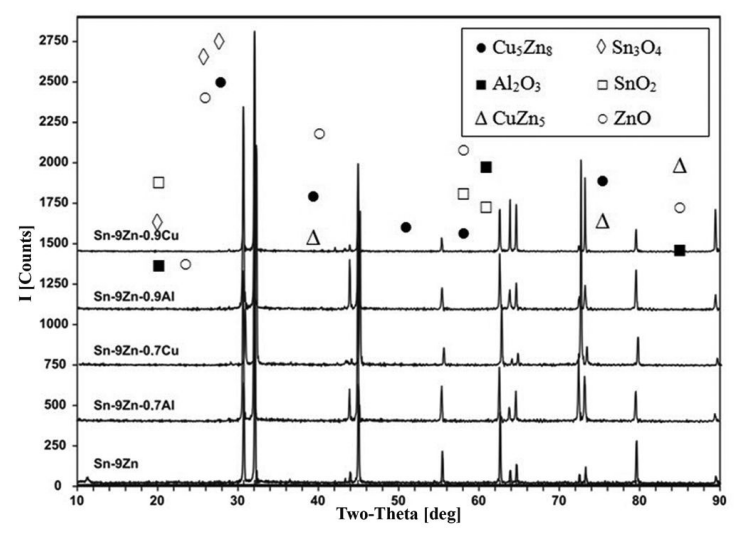

Fig. 2. XRD results of eutectic Sn-9Zn alloy obtained by adding different amounts of $\mathrm{Al}$ and $\mathrm{Cu}$.

In the SEM images of the alloys produced by adding $\mathrm{Al}$ to the Sn-9Zn eutectic alloy at different amounts (0.7 and 0.9 wt.\%), it was found that Alrich areas formed in the microstructure. Another study by Das et al. [23] also reported Al-rich areas seen in the microstructure of Sn-Zn-Al alloys. EDS analysis results can be found in Table 2.

It can be seen from the results of EDS analysis given in Table 2 that $\mathrm{Al}_{2} \mathrm{O}_{3}$ intermetallic phase has formed in the structure of Sn-9Zn-0.9Al alloy. The formation of $\mathrm{Al}_{2} \mathrm{O}_{3}$ intermetallic phase in the microstructure of the alloy is thought to be caused by liquid metal contact with atmosphere during melting or casting operations. Although these areas were found to be $\mathrm{Al}_{6} \mathrm{Zn}_{3} \mathrm{Sn}$ in some earlier studies, this intermetallic phase could not be identified by EDS and XRD examinations [24, 25]. Again, based on EDS (Table 2) and XRD results in Fig. 2 it can be stated that $\mathrm{Al}_{2} \mathrm{O}_{3}$ intermetallic phase occurred in the alloy. It is also seen that the pores formed in the microstructure of the alloy were produced by adding $0.9 \mathrm{Al}$ to the $\mathrm{Sn}-9 \mathrm{Zn}$ eutectic alloy.

\subsection{Hardness results}

Movement of dislocations is affected by a microstructure of a material and subsequently affects its hardness. Therefore, microhardness measurements were performed in order to determine 
Table 2. Results of EDS analysis [wt.\%].

\begin{tabular}{lcccccc}
\hline Alloy & Location & Sn & Zn & Cu & Al & O \\
\hline \hline Sn-9Zn & 1 & 98.96 & 1.04 & - & - & - \\
& 2 & 96.37 & 3.63 & - & - & - \\
Sn-9Zn-0.7Cu & 3 & 89.33 & 10.67 & - & - & - \\
& 1 & - & 65.91 & 27.13 & - & 1.25 \\
& 2 & 90.98 & 3.39 & - & - & 2.59 \\
Sn-9Zn-0.9Cu & 3 & 67.47 & 15.47 & 5.4 & - & 3.7 \\
& 1 & - & 72.83 & 19.20 & - & 1.2 \\
& 2 & 72.56 & 26.53 & - & - & 0.91 \\
Sn-9Zn-0.7Al & 3 & 92.30 & 6.86 & 0.84 & - & - \\
& 1 & 93.68 & 3.86 & - & 2.46 & - \\
Sn-9Zn-0.9Al & 2 & 99.43 & 0.52 & - & 0.05 & - \\
& 1 & 37.5 & 3.93 & - & 14.88 & 29.18 \\
& 2 & 91.2 & 3.61 & - & - & 2.89 \\
\hline
\end{tabular}

microstructural differences between $\mathrm{Sn}-\mathrm{Zn}$ and $\mathrm{Sn}$ $\mathrm{Zn}-\mathrm{xCu} / \mathrm{Al}$ alloys produced by investment casting method. Microhardness changes in the alloys can be found in Fig. 3.

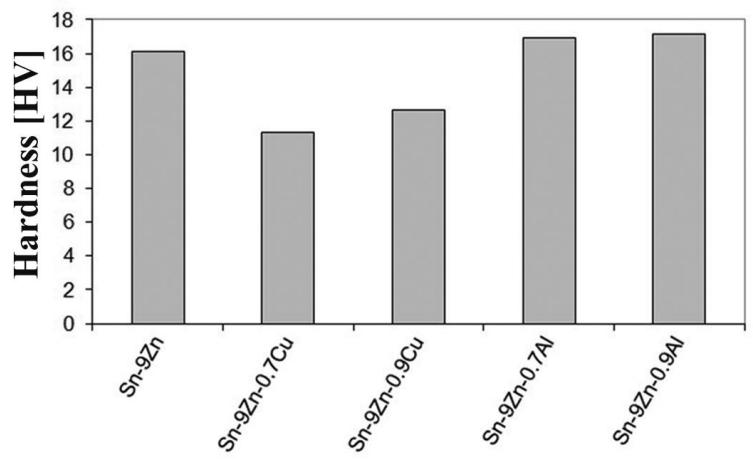

Alloys

Fig. 3. Microhardness changes in $\mathrm{Sn}-\mathrm{Zn}$ and $\mathrm{Sn}-\mathrm{Zn}$ $\mathrm{xCu} / \mathrm{Al}$ alloys.

It was observed that the hardness of Sn-9Zn$\mathrm{xCu}$ alloys decreased when the addition of $\mathrm{Cu}$ increased to $0.7 \%$ or $0.9 \%$. When the amount of $\mathrm{Al}$ in the $\mathrm{Sn}-9 \mathrm{Zn}$ eutectic alloy increased from $0.7 \%$ to $0.9 \%$, the hardness of the alloy increased as well. In addition to the two-phased structure of Sn9Zn alloy, a third phase appeared in the structure with the addition of $\mathrm{Cu}$. The hardness of the alloy decreased due to weak areas formed between the complex-shaped $\mathrm{Cu}_{5} \mathrm{Zn}_{8}$ IMCs and the matrix. It can be understood from the microstructure SEM images (Fig. 1) that an increase in $\mathrm{Cu}$ amount resulted in an increase in the size and amount of $\mathrm{Cu}_{5} \mathrm{Zn}_{8}$ intermetallic phases. Therefore, a slight increase in hardness was observed for $0.9 \% \mathrm{Cu}$ added alloy. When $\mathrm{Al}$ was added to the $\mathrm{Sn}-9 \mathrm{Zn}$ eutectic alloy at different amounts, on the other hand, it was seen that the addition of $\mathrm{Al}$ increased the hardness of the alloy (compared to the hardness value of $\mathrm{Sn}-9 \mathrm{Zn}$ eutectic alloy). Although the intermetallic phases observed in this study were described as $\mathrm{Al}_{6} \mathrm{Zn}_{3} \mathrm{Sn}$ in some earlier studies [2326], these intermetallic phases could not be identified as a result of EDS analysis and XRD examinations in this study. Again based on EDS and XRD results, it was concluded that $\mathrm{Al}_{2} \mathrm{O}_{3}$ was this intermetallic phase. It is also seen that the pores formed in the microstructure of the alloy were produced by adding $0.9 \mathrm{Al}$ to the Sn-9Zn eutectic alloy.

\subsection{Tensile test results}

Tensile tests are performed in order to measure resistance of a material against plastic deformation. The transition from elastic behavior to plastic behavior cannot be easily determined for some materials. Results of the tensile test performed on Sn$9 \mathrm{Zn}$ and $\mathrm{Sn}-9 \mathrm{Zn} \times \mathrm{Cu} / \mathrm{Al}$ solder alloys can be found in Fig. 4. 


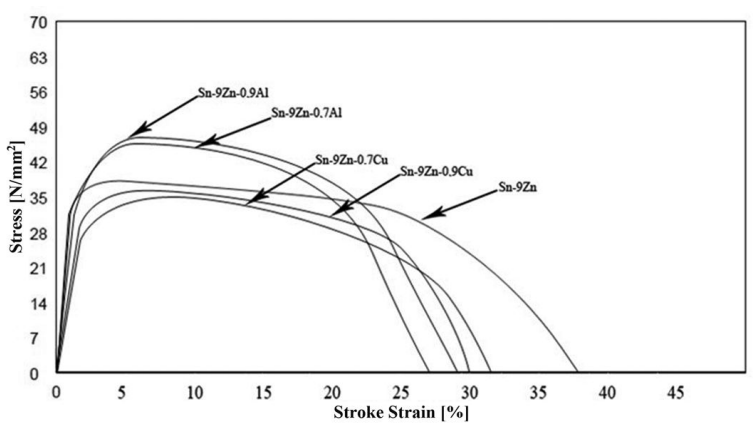

Fig. 4. Tensile stress-strain curves of Sn-9Zn, Sn-9Zn$0.7 \mathrm{Cu}, \mathrm{Sn}-9 \mathrm{Zn}-0.9 \mathrm{Cu}, \mathrm{Sn}-9 \mathrm{Zn}-0.7 \mathrm{Al}$ and Sn9Zn-0.9Al alloys.

According to the tensile test results given in Fig. 4, the measured tensile strengths of the alloys were $38 \mathrm{MPa}(\mathrm{Sn}-9 \mathrm{Zn}), 35 \mathrm{MPa}(\mathrm{Sn}-9 \mathrm{Zn}-0.7 \mathrm{Cu})$, $37 \mathrm{MPa}(\mathrm{Sn}-9 \mathrm{Zn}-0.9 \mathrm{Cu}), 45 \mathrm{MPa}$ (Sn-9Zn-0.7Al) and $46 \mathrm{MPa}$ (Sn-9Zn-0.9Al). These results show that when $0.7 \% \mathrm{Cu}$ was added to the $\mathrm{Sn}-9 \mathrm{Zn}$ eutectic alloy, the tensile strength decreased while a slight increase in the strength was observed by adding $0.9 \%$ wt. $\mathrm{Cu}$. As the amount of added $\mathrm{Cu}$ increased, a slight increase in tensile strength was observed. A comparison of tensile test results with the microstructure images (Fig. 1) and XRD results (Fig. 2) reveals that $\mathrm{Cu}_{5} \mathrm{Zn}_{8}$ IMC phase is the factor that causes the tensile strength to decrease. As the amount of $\mathrm{Cu}$ added to the $\mathrm{Sn}-9 \mathrm{Zn}$ increased, the size of IMCs formed in the structure increased as well. While the tensile strength slightly increased in parallel with the increase in the size of the intermetallics in the structure of the alloys, the percentage elongation decreased slightly. In spite of this, the tensile strength of the $0.9 \% \mathrm{Cu}$ added alloy, which had the highest tensile strength among $\mathrm{Cu}$ added alloys, was lower compared to the eutectic alloy (Sn-9Zn). This is due to the notch effect observed in the structure of the alloy caused by the third phase (intermetallics) formed in the structure of the alloy during pouring and solidification. Due to this notch effect, high tension areas developed under tension, especially in tips of intermetallics and these high tension areas led to microcracks (under increased tension). These microcracks in the structure grew bigger with the increasing load and caused fractures [27, 28]. Among $\mathrm{Al}$ added eutectic Sn-9Zn alloys, on the other hand, Sn-9Zn$0.9 \mathrm{Al}$ alloy had the highest tensile strength. Accordingly, the maximum tensile strength of the alloys increased as the amount of $\mathrm{Al}$ added to the Sn$9 \mathrm{Zn}$ eutectic alloy increased. SEM images of fractured surfaces of $\mathrm{Sn}-9 \mathrm{Zn}$ and $\mathrm{Sn}-9 \mathrm{Zn} \times \mathrm{Cu} / \mathrm{Al}$ alloys obtained as a result of tensile test can be found in Fig. 5.

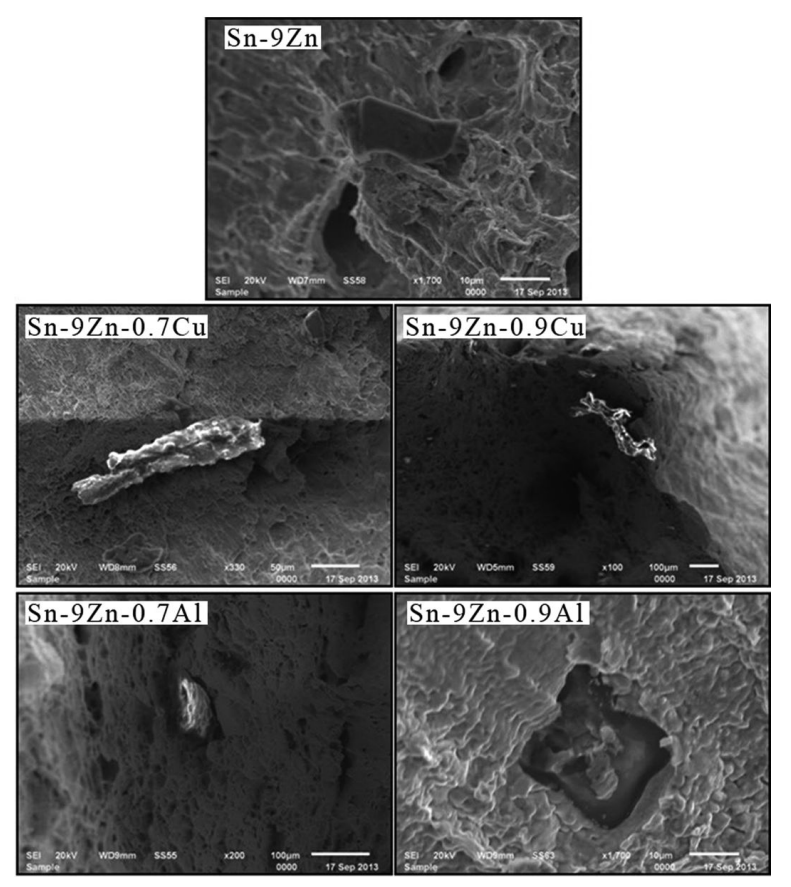

Fig. 5. SEM images of fractured surfaces of Sn-9Zn and $\mathrm{Sn}-9 \mathrm{Zn} \times \mathrm{Cu} / \mathrm{Al}$ alloys.

Since the alloys were prepared and poured in atmospheric conditions, various oxides formed due to the contact of liquid metal with atmosphere during the pouring. Also, the pores formed in slow solidification conditions had some effect on the fracture. In other words, micro and macro defects occurring in the structure of the alloy contribute to fracture. Aluminum oxide formation was observed in the fracture areas of $\mathrm{Al}$ added alloys. Due to the tensile stress created during tensile tests, the fracture started from $\beta$-Sn and eutectic area, and the areas where intermetallics such as aluminum oxide was present. It was seen from the fracture surfaces of the samples that ductile fracture mode occurred in all alloys. It can be concluded from the SEM images that intermetallic compounds formed during 
pouring increased tensile strengths of alloys, while decreased ductility.

\subsection{Weibull statistical analysis}

Weibull statistical analysis was performed using the data obtained from tensile tests. The Weibull probability distribution was estimated using the graphical method. The Weibull probability distribution of $\mathrm{Sn}-9 \mathrm{Zn}$ and $\mathrm{Sn}-9 \mathrm{Zn} \times \mathrm{Cu} / \mathrm{Al}$ alloys can be seen in Fig. 6.

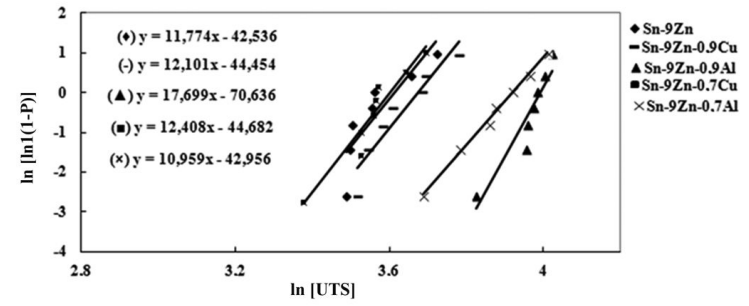

Fig. 6. Weibull modules of $\mathrm{Sn}-9 \mathrm{Zn}$ and $\mathrm{Sn}-9 \mathrm{Zn} \times \mathrm{Cu} / \mathrm{Al}$ alloys.

Tensile strength and percentage elongation values obtained from tensile tests were used to determine two-dimensional Weibull distribution and quality index. Two-dimensional Weibull distribution is a simple and useful statistical method used to determine the reliability of materials. The tensile strength data obtained with this method were sorted from low to high and the corresponding $\ln$ values (ln tensile and/or ln percentage elongation) were plotted on the $\mathrm{x}$ axis of the graph.

Weibull modules of eutectic Sn-9Zn alloy obtained by adding different amounts of $\mathrm{Al}$ and $\mathrm{Cu}$ were calculated according to tensile test results. The Weibull modules of the Sn-9Zn alloy, $0.7 \%$ $\mathrm{Al}$ added alloy and $0.9 \% \mathrm{Al}$ added alloy were calculated as $11.77,10.95$ and 17.69 respectively. According to tensile strength formation frequencies (see Table 3), it was found that the increased amount of $\mathrm{Al}$ addition positively affects the formation frequency. Das et al. [26] reported that $0.5 \%$ $\mathrm{Al}$ addition increased tensile strength and elongation values of the alloy. This increase in tensile strength and elongation values is due to the dispersion hardening that occurs in the structure of the alloy. The dispersion hardening can be explained as second phases (intermetallics) formed in grain boundaries, hampering dislocation and consequently, increasing the tensile strength of the alloy. It was found that the tensile strength and Weibull module increased as the amount of aluminum added to the Sn-9Zn alloy increased. The Weibull module was calculated as 12.40 with the addition of $0.7 \% \mathrm{Cu}$, and 12.10 with the addition of $0.9 \% \mathrm{Cu}$. Although a slight increase occurred in tensile strength and elongation values, it was not remarkable. Considering tensile strength formation frequencies, the increase in the amount of $\mathrm{Cu}$ addition adversely affected the formation frequency.

\section{Conclusion}

- It was observed that the size of IMC phase increased as the amount of $\mathrm{Cu}$ increased and that the $\alpha-\mathrm{Zn}$ phase, which occurs in the area between these phases and the main matrix, is thinner.

- It was found from the XRD examination that $\mathrm{Cu}_{5} \mathrm{Zn}_{8}$ phase formed in the $\mathrm{Sn}-9 \mathrm{Zn}-\mathrm{xCu}$ alloys, but $\mathrm{CuZn}_{5}$ formed only in the Sn-9Zn$0.9 \mathrm{Cu}$ alloy.

- It was determined that the hardness value increased as the addition of $\mathrm{Cu}$ increased in $\mathrm{Sn}-9 \mathrm{Zn}-\mathrm{xCu}$ alloys. However, even the hardest alloy, Sn-9Zn-0.9Cu, did not reach the hardness value of the Sn-9Zn eutectic alloy.

- It was found that the hardness value increased as the $\mathrm{Al}$ amount increased in $\mathrm{Sn}$ 9Zn-xAl alloys and the hardness values of both $\mathrm{Al}$ added alloys were higher compared to the $\mathrm{Sn}-9 \mathrm{Zn}$ eutectic alloy.

- According to results of tensile tests, the highest tensile strength was obtained with the addition of $\mathrm{Al}$ to the Sn-9Zn eutectic alloy. It was determined that the percentage elongation value slightly decreased with increasing amount of $\mathrm{Al}$ addition.

- It was determined that the Weibull module increased in parallel with the amount of $\mathrm{Al}$ addition to the $\mathrm{Sn}-\mathrm{Zn}$ alloy and 
Table 3. Tensile strength and percentage elongation values of $\mathrm{Sn}-9 \mathrm{Zn}$ and $\mathrm{Sn}-9 \mathrm{Zn} \times \mathrm{Cu} / \mathrm{Al}$ alloys.

\begin{tabular}{lccccc}
\hline & Sn-9Zn & Sn-9Zn-0.9Cu & Sn-9Zn-0.9Al & Sn-9Zn-0.7Cu & Sn-9Zn-0.7Al \\
\hline \hline Range of UTS [MPa] & $33-41$ & $33-44$ & $45-56$ & $29-40$ & $40-55$ \\
Average of UTS [MPa] & 36 & 38 & 53 & 35 & 48 \\
Standard deviation of UTS & 3.25 & 3.60 & 3.21 & 3.22 & 5.16 \\
Range of E [\%] & $6.80-13.52$ & $3.6-14.06$ & $6.77-13.31$ & $8.28-16.82$ & $9.04-11.53$ \\
Average of E [\%] & 8.95 & 7.96 & 10.23 & 11.68 & 10.77 \\
Standard deviation of E [\%] & 2.32 & 4.03 & 2.30 & 3.35 & 0.82 \\
Weibull moduls & 11.7 & 12.10 & 17.69 & 12.40 & 10.95 \\
\hline
\end{tabular}

the addition of $\mathrm{Al}$ had a positive effect on the tensile strength and reliability of the alloy.

\section{References}

[1] Mahmudi R., Geranmayeh A.R., Noori H., ShaHABI M., Mater. Sci. Eng. A, 491 (2008), 110.

[2] SaAd G., Fawzy A., Shawky E.J., Alloy. Compd., 479 (2009), 844.

[3] HAMMAD A.E., Mater. Des., 50 (2013), 108.

[4] Luo T., Chen Z., Hu A., Li M., Mater. Sci. Eng. A, 556 (2012), 885.

[5] Mahmudi R., FARASheh D., Microelectron Reliab., 54 (2014), 1592.

[6] Song J.M., Lui T.S., LAn G.F., Chen L.H., J. Alloy. Compd., 379 (2004), 233.

[7] El-Daly A.A., Hammand A.E., J. Alloy. Compd., 509 (2011), 8554.

[8] Garcia L.R., Osorio W.R., PeiXoto L.C., GarCIA A., Mater. Charact., 61 (2010), 212.

[9] ÇAdirli E., BÖYÜK U., Engin S., KaYA H., Maraşli N., Ülgen A., J. Alloys. Compd., 486 (2009), 199.

[10] Islam R.A., Chan Y.C., Jillek W., Islam S., Microelectron J., 37 (2006), 705.

[11] Shalaby R.M., Mater. Sci. Eng. A, 550 (2012), 112.

[12] Abtew M. Selvaduray G., Mater. Sci. Eng., 27 (2000), 95.

[13] El-Daly A.A., Hammad A.E., J. Alloys. Compd., 505 (2010), 793.

[14] Wei X., Huang H., Zhou L., Zhang M., LiU X., Mater. Lett., 61 (2007), 655.

[15] FAWZY A., Mater. Charact., 58 (2007), 323.
[16] Jing Y., Sheng G., Zhao G., Mater. Des., 52 (2013), 92.

[17] Osorio W.R., Peixoto L.C., Garcia L.R., Noel N.M., Garcia A., J. Alloys. Compd., 572 (2013), 97.

[18] Freitas E.S., Osorio W.R., SPINElli J.E., GARCIA A., Microelectron Reliab., 54 (2014), 1392.

[19] El-Daly A.A., Swilem Y., MaKled M.H., ElShaArawy M.G., ABDraboH A.M., J. Alloys. Compd., 484(2009), 134.

[20] Billah Md.M., Shorowordi K.M., Sharif A., J. Alloys. Compd., 585 (2014), 32.

[21] Yang L., Zhang Y., Du C., Dai J., Zhang N., Microelectron Reliab., 55 (2015), 596.

[22] El-Daly A.A., Hammad A.E., Al-Ganainy G.S., IBRAHIEM A.A., Mater. Des., 56 (2014), 594.

[23] Das S.K., Sharif A., Chan Y.C., Wong N.B., YUNG W.K.C., J. Alloys. Compd., 481 (2009), 167.

[24] Billah Md.M., Alam T., Hossain M.A., SHARIF A., ISLAM S.M.K.N., ICME11-AM-016 Proc. Int. Conf. Mech. Eng., Dhaka, Bangladesh, Dec. (2011), 1.

[25] Chen K.I., Cheng S.C., Wu S., Lin K.L., J. Alloy. Compd., 416 (2006), 98.

[26] Das S.K., Sharif A., Chan Y.C., Wong N.B., YUNG W.K.C., Micrelectron Eng., 86 (2009), 2086.

[27] LuO T., Hu A., Hu J., MAO D., Microelectron Reliab., 52 (2012), 585.

[28] Ahemed M., Fouzder T., Sharif A., Gain A.K., CHAN Y.C., Microelectron Reliab., 50 (2010), 1134. 